\title{
Mechanochemical Synthesis of $\mathrm{BaTiO}_{3}$ Powders and Evaluation of Their Acrylic Dispersions
}

\author{
Sonia Kudłacik-Kramarczyk ${ }^{1, *}$, Anna Drabczyk ${ }^{1, *}$, Magdalena Głąb ${ }^{1}$, Piotr Dulian ${ }^{2} \mathbb{D}$, \\ Rafał Bogucki ${ }^{1}$, Krzysztof Miernik ${ }^{1}$, Agnieszka Sobczak-Kupiec ${ }^{1}$ and Bożena Tyliszczak ${ }^{1, * \text { (D) }}$ \\ 1 Institute of Materials Science, Faculty of Materials Engineering and Physics, Cracow University of Technology, \\ 37 Jana Pawła II Av., 31-864 Krakow, Poland; magdalenaglab@op.pl (M.G.); rbogucki@mech.pk.edu.pl (R.B.); \\ kmiernik@pk.edu.pl (K.M.); agnieszka.sobczak-kupiec@pk.edu.pl (A.S.-K.) \\ 2 Institute of Inorganic Chemistry and Technology, Faculty of Chemical Engineering and Technology, \\ Cracow University of Technology, 24 Warszawska St., 31-155 Krakow, Poland; piotr.dulian@pk.edu.pl \\ * Correspondence: sonia.kudlacik-kramarczyk@pk.edu.pl (S.K.-K.); anna.drabczyk2@pk.edu.pl (A.D.); \\ bozena.tyliszczak@pk.edu.pl (B.T.)
}

Received: 20 June 2020; Accepted: 21 July 2020; Published: 23 July 2020

check for updates

\begin{abstract}
Barium titanate is a ferroelectric perovskite with unique electric properties; therefore, it is widely applied in the fabrication of inorganic coatings or thin films, capacitors, or in the production of devices for energy storage and conversion. This paper describes the mechanochemical synthesis of $\mathrm{BaTiO}_{3}$ from $\mathrm{BaO}$ and $\mathrm{TiO}_{2}$ using a ball mill. XRD analysis allowed concluding that barium titanate was formed after $90 \mathrm{~min}$ of mechanochemical grinding. It was also proved by spectroscopic analysis and the band corresponding to Ti-O vibrations on obtained Fourier Transform Infrared (FT-IR) spectra. The specific surface area of obtained powder was $25.275 \mathrm{~m}^{2} / \mathrm{g}$. Next, formed perovskite was dispersed in an acrylic poly(ethylene glycol) (superabsorbent polymer suspension, SAP) suspension prepared using microwave radiation. Final suspensions differed in the concentration of SAP applied. It was proven that the increase of SAP concentration does not affect the acidity of the suspension, but it does increase its dynamic viscosity. A sample with $83 \mathrm{wt}$.\% of SAP reached a value of approximately $140 \mathrm{mPa} \cdot \mathrm{s}$. Dispersions with higher values of SAP mass fraction exhibited lower sedimentation rates. Molecules such as SAP may adsorb to the surface of particles and thus prevent their agglomeration and make them well monodispersed. Based on the performed experiments, it can be concluded that acrylic poly(ethylene glycol) suspension is a suitable fluid that may stabilize barium titanate dispersions.
\end{abstract}

Keywords: barium titanate; perovskite powders; mechanochemical synthesis; acrylic poly(ethylene glycol) dispersions; microwave irradiation; sedimentation process

\section{Introduction}

Barium titanate is an inorganic compound that due to its interesting properties has attracted particular attention recently. This is a ferroelectric perovskite with a wide area of applications [1]. Its interesting properties result from its different forms, depending on the temperature. Within the temperature range of $0-130{ }^{\circ} \mathrm{C}$, the ferroelectric tetragonal phase of $\mathrm{BaTiO}_{3}$ is stable, and when the temperature is above $130{ }^{\circ} \mathrm{C}$, it shows stability in a paraelectric cubic phase [2]. Particularly interesting is the use of barium titanates for the fabrication of capacitors or ultracapacitors. For example, Reynolds et al. reported on the application of sputtered modified $\mathrm{BaTiO}_{3}$ for the preparation of thin-film capacitors. The authors proved that such capacitors were characterized by dielectric loss and a significant leakage [3]. Next, Wodecka-Duś et al. presented ceramic materials based on lanthanum-doped barium titanate with good electrical permittivity that may be applied for the fabrication of ultracapacitors [4]. The high electrical permittivity of ferroelectric $\mathrm{BaTiO}_{3}$ was noticed also by Wu et al., who applied the microparticles 
of this compound for the preparation of filaments applied for fused deposition modeling, i.e., one of the 3D printing techniques. Applied filaments consisted of polymer matrix based on acrylonitrile butadiene styrene and barium titanate microparticles, which were introduced into such a matrix. As result, microwave devices characterized by a high dielectric permittivity have been printed [5].

Barium titanates have also found applications in the preparation of piezoelectric devices. For example, Wei et al. described investigations on the sintered piezoelectric ceramic based on barium titanate. This inorganic compound has been processed using extrusion free-forming from milled precursors. As a result, ceramic material with promising piezoelectric and dielectric properties has been obtained [6]. Barium titanate has also been used for the fabrication of silicone elastomers to form dielectric elastomers with good permittivity and mechanical properties [7]. Another application has been proposed by Uttan et al. They carried out investigations on a discotic liquid crystalline material prepared using ferroelectric nanoparticles of barium titanate. The introduced $\mathrm{BaTiO}_{3}$ nanoparticles affected the thermal stability of the material and caused the decrease of its permittivity [8]. Next, Giannakoudakis et al. proposed the deposition of the homogeneous coating formed from barium titanate nanospheres on the carbon textile fibers. They reported that such a formed composite may be useful as an efficient protection material against the toxic vapors [9]. Another use of barium titanate was described by Yang et al. They formed a core-shell filler based on $\mathrm{BaTiO}_{3}$ and nickel hydroxide and dispersed such a filler in the poly(vinylidene fluoride-hexafluoropropylene) matrix [10]. Additionally, barium compounds are used for optical measurements [11].

The ferroelectric properties of barium titanate have been also taken into account during the designing of the materials fabricated for the energy storage application [12-14] or the energy conversion [15]. On the other hand, barium titanate has also found wide application in medicine, e.g., in tissue engineering [16-21]. Different methodologies for the fabrication of barium titanate/hydroxyapatite scaffold, e.g., multistage spark plasma sintering [22], hydrothermal process [23], or pulsed laser deposition [24], have been investigated.

In the case of preparation methods of barium titanate, the mechanochemical synthesis of this compound is the research subject of many investigations. Such a methodology may reduce the size of the particles obtained and allows receiving nano-sized powders [25]. Such a synthesis was presented by Lazarevic et al. [26], Sydorchuk et al. [27], and Ohara et al. [28]. Many investigations have been also performed on the suspensions of barium titanate [29,30] and the stability of such suspensions [31,32].

$\mathrm{BaTiO}_{3}$ is most widely used in making multilayer ceramic capacitors (MLCC), thermistors, and piezoelectric sensors. The inkjet printing (IJP) process can be used to fabricate MLCC of complex configurations by integrating internal electrodes and dielectric layers in a single step using a multi printing-head system. Stabilized aqueous suspensions of $\mathrm{BaTiO}_{3}$-based powders are required to obtain dielectric inks adapted to IJP. There is no information in the scientific literature on stabilized solutions of barium titanate prepared by mechanochemical synthesis. One of the characteristic features of the ceramic material obtained in this way is its fragmentation and a large number of structural defects, which may result in different properties in water suspensions. One of the goals of the research is to explore the possibility of preparing stabilized suspensions of $\mathrm{BaTiO}_{3}$ powders made by unconventional synthesis method using high-energy milling devices.

In the research, barium titanate has been synthesized using $\mathrm{BaO}$ and $\mathrm{TiO}_{2}$ subjected to mechanochemical grinding. Subsequently, the obtained perovskite powder has been dispersed in superabsorbent polymer suspension (SAP) based on acrylic poly(ethylene glycol), and the process was supported by microwave radiation. Final suspensions differed in the concentration of SAP applied. Both prepared perovskite powder and obtained dispersions have been investigated. The process of perovskite synthesis was evaluated using XRD analysis, its structure was characterized by Fourier Transform Infrared (FT-IR) spectroscopy, the morphology was assessed by SEM technique, and the specific surface area was determined by Brunauer, Emmett and Teller (BET) physical adsorption isotherms. Next, investigations on the impact of SAP concentrations on the $\mathrm{pH}$, sedimentation process, 
and the dynamic viscosity of the suspension formed were performed. Additionally, the $\mathrm{pH}$ and zeta potential measurements of aqueous suspension of barium titanate have been performed.

\section{Materials and Methods}

\subsection{Materials}

Barium oxide (powder, 97\%), potassium hydroxide (powder), acrylic acid $(99 \%, \mathrm{~d}=1.051 \mathrm{~g} / \mathrm{mL}$, anhydrous, contains $200 \mathrm{ppm}$ Mequinol (MEHQ) as inhibitor), ammonium persulfate (98\%), poly(ethylene glycol), and $N, N^{\prime}$-methylenebis(acrylamide) were bought from Sigma Aldrich (Saint Louis, MO, USA) $\mathrm{TiO}_{2}$ (powder, 98\%) was bought from Evonik Degussa P25 GmbH (Essen, Germany).

\subsection{Applied Methodology}

In order to receive $\mathrm{BaTiO}_{3}$ with a homogeneous structure, the oxides used for its preparation were first heat treated to remove hydroscopic water and then mixed before grinding in a stoichiometric ratio using an agate mortar. Next, such prepared mixture was mechanochemically treated in a high-energy planetary ball mill Activator 2S (Activator Corporation, Novosibirsk, Russia). Milling was conducted at room temperature in air. A $250 \mathrm{~mL}$ reaction vessel was used, along with $\mathrm{Cr}-\mathrm{Ni}$ steel ball bearings of $10 \mathrm{~mm}$ in diameter. The vessel was rotated at $1100 \mathrm{rpm}$ for $1.5 \mathrm{~h}$, with a ball-to-powder weight ratio (BPR) equal 40:1 [33-35]. The scheme of the preparation of barium titanate $\mathrm{BaTiO}_{3}$ has been presented in Figure 1 below.

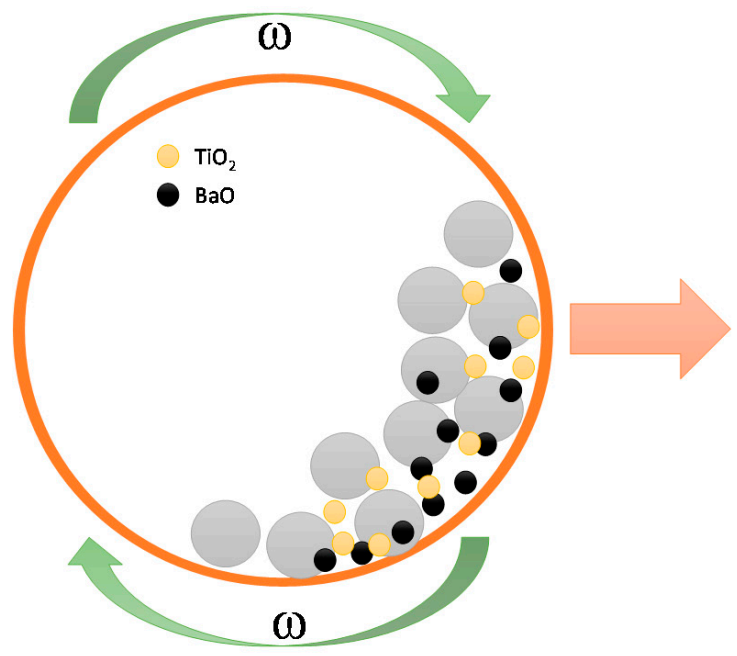

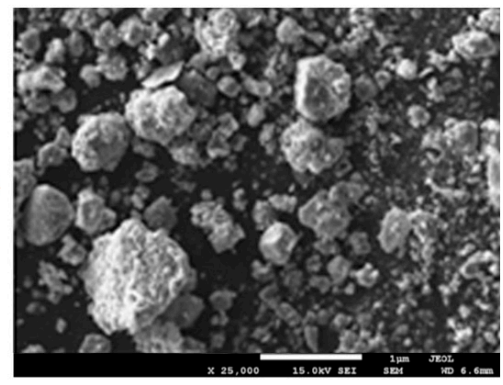

$\mathrm{BaTiO}_{3}$

Figure 1. The scheme of the preparation of $\mathrm{BaTiO}_{3}$ using a ball mill.

The acrylic poly(ethylene glycol) suspensions (SAP) were prepared using microwave irradiation. The appropriate amount of acrylic acid, potassium hydroxide, and poly(ethylene glycol) were mixed. Subsequently, the crosslinking agent (i.e., $N, N^{\prime}$-methylenebisacrylamide) and initiator (i.e., ammonium persulfate) were introduced. Finally, the reaction mixture was treated with microwave irradiation (reactor produced by Milestone Srl., power $600 \mathrm{~W}$, Sorisole, Italy) for $3 \mathrm{~min}$. The temperature of the reaction mixture was maintained between 90 and $95{ }^{\circ} \mathrm{C}$. The SAP suspension obtained was characterized by a solid, very viscous, and uniform jelly-like structure [33-35]. The scheme of the preparation of the dispersion by mixing adequate amounts of $\mathrm{BaTiO}_{3}$ and acrylic poly(ethylene glycol) suspension of SAP is shown below in Figure 2. 


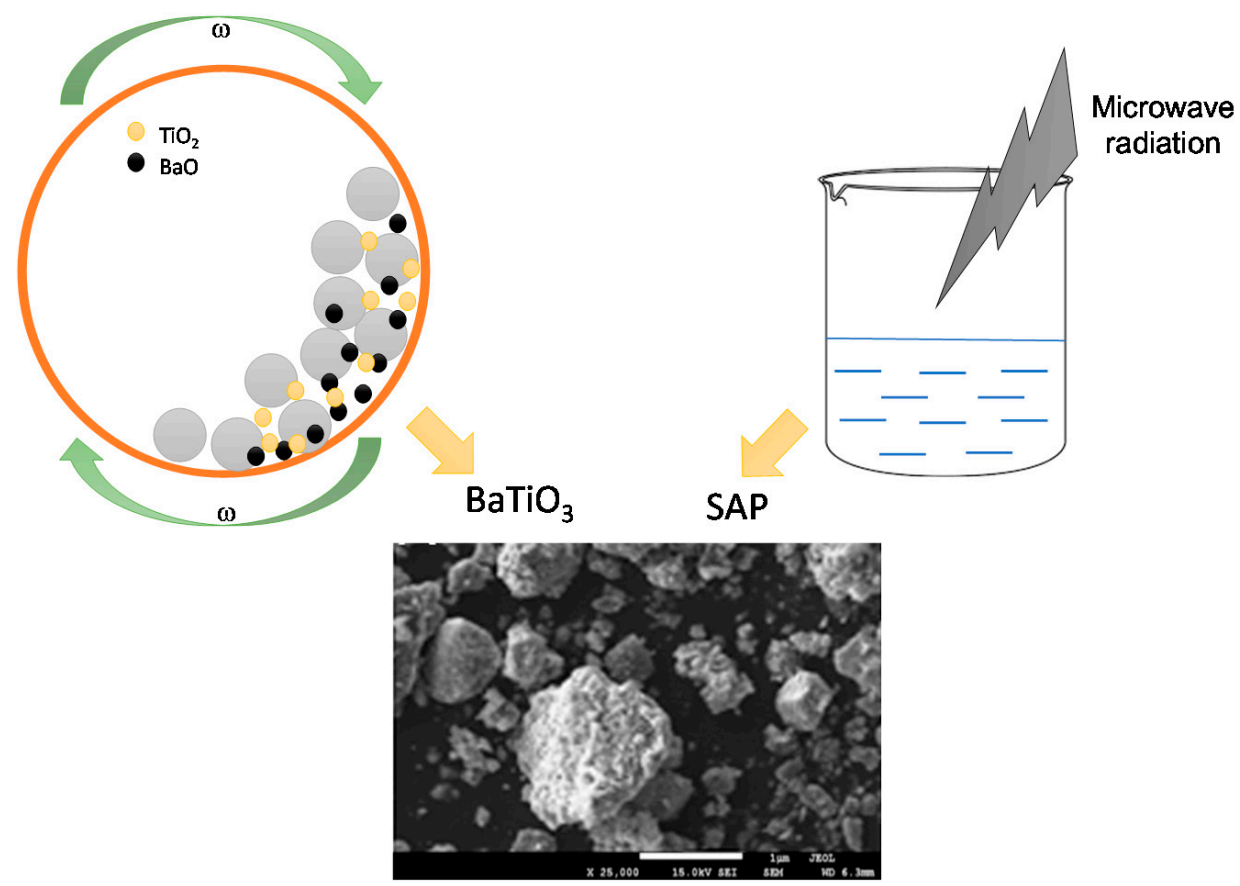

Figure 2. The scheme of the preparation of the dispersion of $\mathrm{BaTiO}_{3}$ stabilized by superabsorbent polymer suspension (SAP).

During the syntheses, the amount of barium titanate used was constant, while the amounts of SAP applied was changed. The compositions of the obtained dispersions are presented in Table 1.

Table 1. Composition of the $\mathrm{BaTiO}_{3}$ suspension stabilized by SAP.

\begin{tabular}{cccc}
\hline $\mathrm{BaTiO}_{3}[\mathrm{~g}]$ & Distilled Water $[\mathrm{mL}]$ & SAP $[\mathrm{g}]$ & SAP $[w t . \%]$ \\
\hline & 0 & 0 \\
\multirow{2}{*}{1.0} & \multirow{2}{*}{100} & 1.00 & 50 \\
& & 2.00 & 67 \\
& 3.00 & 75 \\
& 4.00 & 80 \\
& 5.00 & 83 \\
\hline
\end{tabular}

Prepared perovskite powders as well as the obtained dispersion of barium titanate in SAP were subsequently characterized using various methods.

Firstly, the phase composition of barium titanates was identified by X-ray Diffractometry using a Philips X'Pert diffractometer (Eindhoven, The Netherlands) with $\mathrm{Cu} \mathrm{K} \alpha$ radiation $(\lambda=0.15418 \mathrm{~nm})$ and an Ni filter (Philips, Eindhoven, The Netherlands) equipped with graphite monochromator PW $1752 / 00$ operating at $30 \mathrm{kV}$ and $30 \mathrm{~mA}$. The diffraction patterns were recorded in the $2 \theta$ range from $10^{\circ}$ to $90^{\circ}$ with a step size of $0.01^{\circ}$. The material was identified by comparing the obtained patterns with Join Committee for Powder Diffraction Standards (JCPDS) data.

The structure of the obtained powder was characterized by Fourier transform infrared spectroscopy. Such a study was carried out to identify the product of the performed process and determine the functional groups in its structure. Investigations were conducted by a Spectrum 65 (Perkin Elmer, Waltham, MA, USA) spectrometer that was equipped with an attenuated total reflection (ATR) attachment with a diamond/ZnSe crystal. The FT-IR spectra were recorded within the range of $3500-500 \mathrm{~cm}^{-1}$ (32 scans, $4.0 \mathrm{~cm}^{-1}$ resolution), and the analysis was carried out at room temperature.

Next, the surface area of perovskite powders received was determined by BET (Brunauer, Emmett and Teller) physical adsorption isotherms. The study was conducted using Accelerated Surface Area and Porosimetry of Micrometrics Analyzer (ASAP) 2020. 
The surface morphology of $\mathrm{BaTiO}_{3}$ received was characterized by a JEOL JSM 7500F SEM (JEOL Ltd., Tokyo, Japan) microscope equipped with an energy-dispersive (EDS) detector (voltage $10 \mathrm{kV}$ ). Samples before analysis were coated with gold (this element was not included in the elemental analysis). EDS analysis was performed to determine the elemental composition of the powder received.

The stability of barium titanate particles in SAP suspension was determined by sedimentation investigations. For this purpose, each suspension was transferred into test tubes, and the initial suspension heights $\left(h_{0}\right)$ were determined. Next, after 1 and $24 h$, the sediment heights $(h)$ were measured again. The $h / h_{o}$ ratios were presented as a function of the SAP concentrations.

The stability of suspensions received was determined by $\mathrm{pH}$ measurements conducted after 10 days from the synthesis as a function of SAP concentration $(50 \%, 67 \%, 75 \%, 80 \%$, and $83 \%$, respectively) and the incubation time ( $24 \mathrm{~h}, 72 \mathrm{~h}, 120 \mathrm{~h}$, and $168 \mathrm{~h}$, respectively). Additionally, analysis of the $\mathrm{pH}$ and zeta potential of aqueous suspension of barium titanate ( $3 \% \mathrm{wt}$.) was performed.

Finally, the dynamic viscosities of the suspensions formed were also measured. The analyses were performed at ambient temperature by means of an Anton Paar CV-2 PP viscosimeter with mandrel R2.

\section{Results and Discussion}

\subsection{Analysis of Barium Titanate Powder Using X-ray Diffraction (XRD) Technique}

The synthesis of barium titanate proceeds according to the following reaction (Equation (1)):

$$
\mathrm{BaO}+\mathrm{TiO}_{2} \rightarrow \mathrm{BaTiO}_{3}(\Delta \mathrm{G}=-158 \mathrm{~kJ} / \mathrm{mol})
$$

After $1.5 \mathrm{~h}$ of high-energy ball milling of $\mathrm{TiO}_{2}$ and $\mathrm{BaO}$ substrate powders, a product consisting of barium titanate was received. The structural changes of such treated powders were determined by XRD technique after $10 \mathrm{~min}, 30 \mathrm{~min}, 60 \mathrm{~min}$, and $90 \mathrm{~min}$, respectively. The obtained XRD patterns are presented in Figure 3.

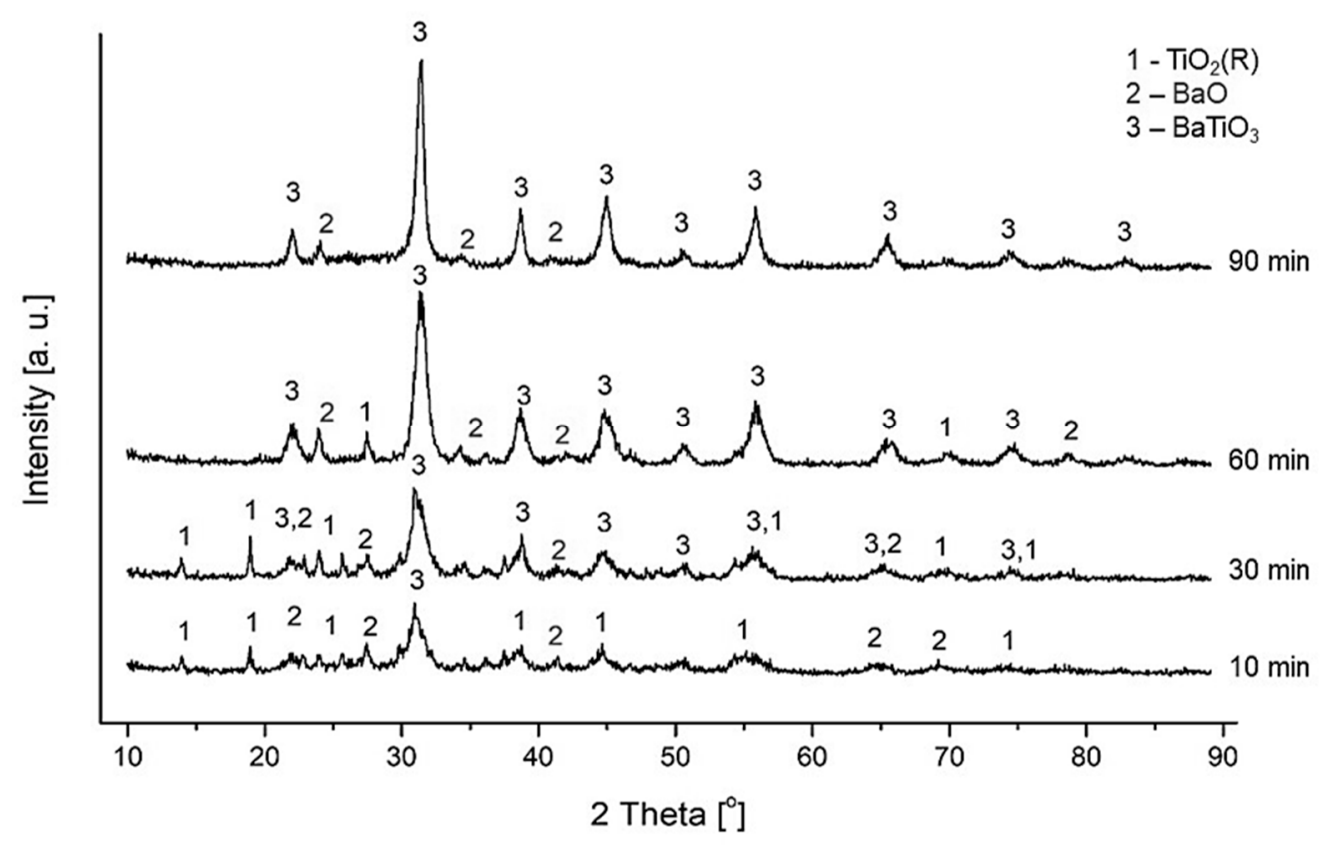

Figure 3. XRD patterns of mechanochemically synthesized barium titanate.

As it may be noticed in Figure 3, 10 min of high-energy mechanochemical treatment of the mixture of $\mathrm{BaO}$ and $\mathrm{TiO}_{2}$ powders lead to the beginning of the formation of crystalline barium titanate. In the first minutes of milling, the disappearance of most diffraction reflections that correspond to the substrates phases is observed. Visible diffraction reflections are characterized by exceptionally low 
intensity. This is due to the high fragmentation of grains and their partial amorphization. After $30 \mathrm{~min}$ of high-energy ball milling, small diffraction reflection at 2Theta angles of 22.18, 31.6, 38.94, 45.26, and 50.95 are visible, indicating the formation of the crystalline $\mathrm{BaTiO}_{3}$ phase. With further milling, most of the diffraction reflections of the substrates disappear. After 90 min of high-energy processing of powders, mainly the barium titanate cubic phase (JCPDS 31-174) is observed. A small amount of a secondary $\mathrm{BaO}$ phase was observed in the ceramics.

\subsection{Analysis of the Structure of Obtained Powder by Fourier Transform Infrared (FT-IR) Spectroscopy}

In Figure 4, the FT-IR spectrum of the obtained powder is shown.

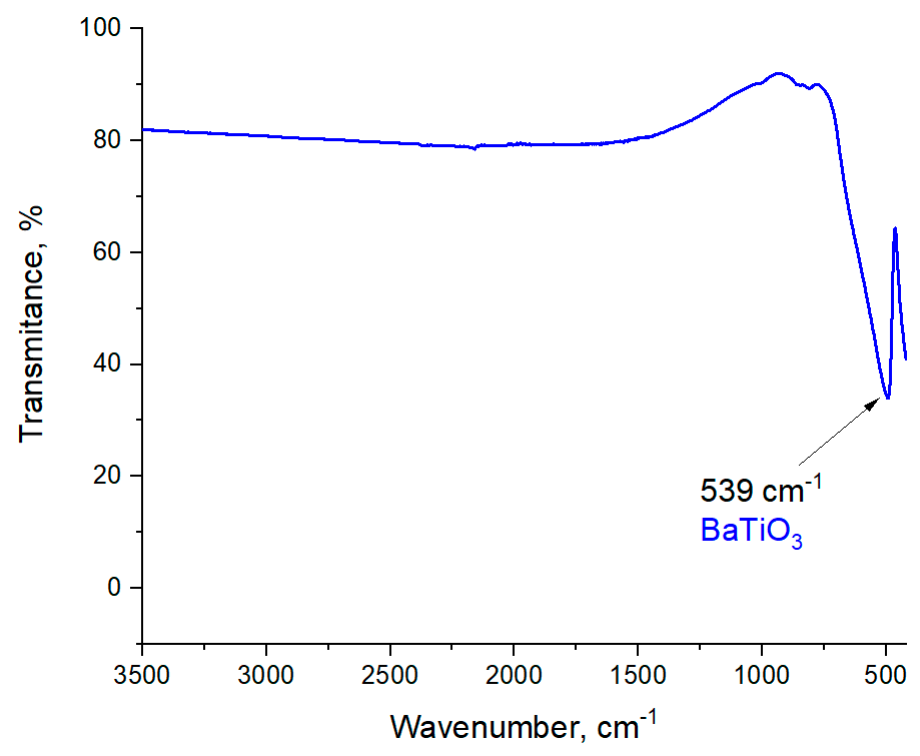

Figure 4. Fourier Transform Infrared (FT-IR) spectrum of barium titanate.

The absorption peak visible at approximately $539 \mathrm{~cm}^{-1}$ corresponds to the stretching vibrations of Ti-O. Such a peak indicates the formation of barium titanate $[36,37]$.

\subsection{Determination of the Specific Surface Area of the $\mathrm{BaTiO}_{3}$ Powders}

The specific surface area is defined as the size of the external surface area of the solid substance per mass of this substance that was presented using the equation below.

$$
\sigma_{\mathrm{m}} \stackrel{\text { def }}{=} \frac{\mathrm{S}}{\mathrm{m}}
$$

where:

S-the external surface area of the solid substance.

$\mathrm{m}$-the mass of the substance.

Such a defined specific surface area is expressed in $\mathrm{m}^{2} / \mathrm{kg}$ or $\mathrm{m}^{2} / \mathrm{g}$.

In Table 2, the results of the BET analysis are presented.

Table 2. The specific surface area of $\mathrm{BaTiO}_{3}$ after $90 \mathrm{~min}$ of the synthesis proceeded in a ball mill.

\begin{tabular}{cc}
\hline Compound & Specific Surface Area, $\mathbf{m}^{2} / \mathbf{g}$ \\
\hline $\mathrm{BaTiO}_{3}$ & 25.275 \\
\hline
\end{tabular}

The specific surface area of barium titanate was $25.275 \mathrm{~m}^{2} / \mathrm{g}$ (Table 2), which was determined by BET adsorption isotherm measurements. Such a value may be determined as low for such types 
of materials. Comparing the previous results of the research presented in Ref. [33], the value of the specific surface area determined for calcium titanate $\mathrm{CaTiO}_{3}$ obtained also by means of the treatment using a ball mill was $38.14 \mathrm{~m}^{2} / \mathrm{g}$. Such a value also has been evaluated as a low one for this type of material.

Further investigations involved analyses using scanning electron microscope that were performed to obtain better images of the surface of the materials received.

\subsection{Scanning Electron Microscope with Energy Dispersive X-ray (SEM-EDS) Spectroscopy}

The research was carried out to determine the morphology and the surface of attained powders. SEM images of $\mathrm{BaTiO}_{3}$ in a form of a dry powder and after the immersion of water are presented in Figure 5. In Figures 6 and 7, SEM-EDS results, including the analysis of the elemental composition and the elemental mapping of tested powder in selected points, have been shown. In turn, in Figure 8, SEM images of barium titanates stabilized by SAP suspensions are shown. Additionally, the size of particular grains has been determined.

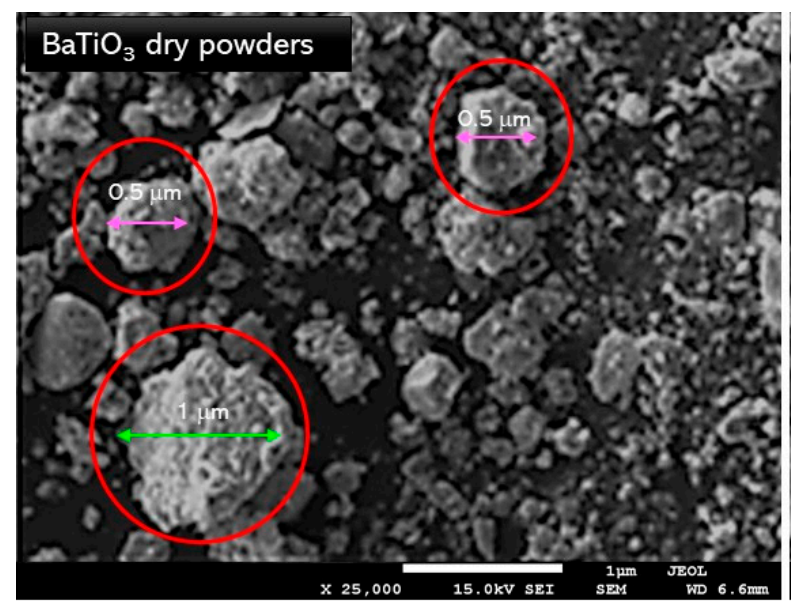

(a)

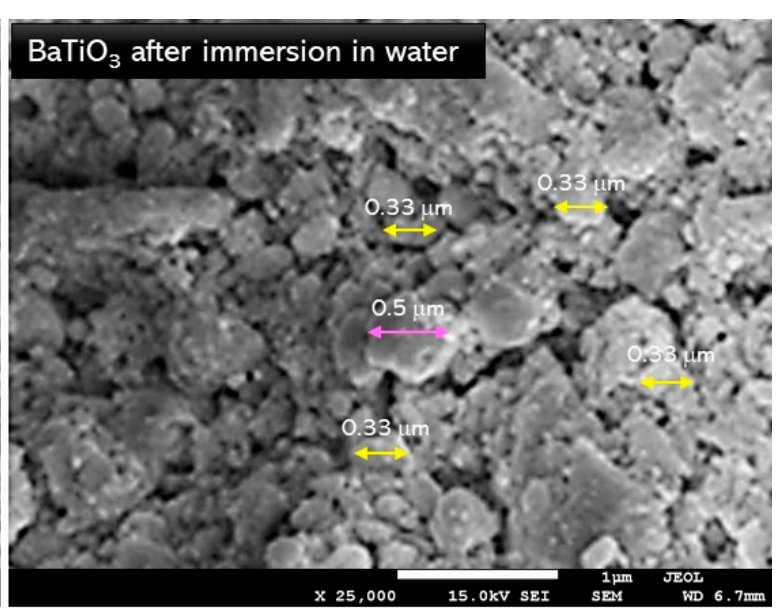

(b)

Figure 5. SEM microphotographs of mechanochemically obtained $\mathrm{BaTiO}_{3}$ powders in dry state (a) and after immersion in water (b).

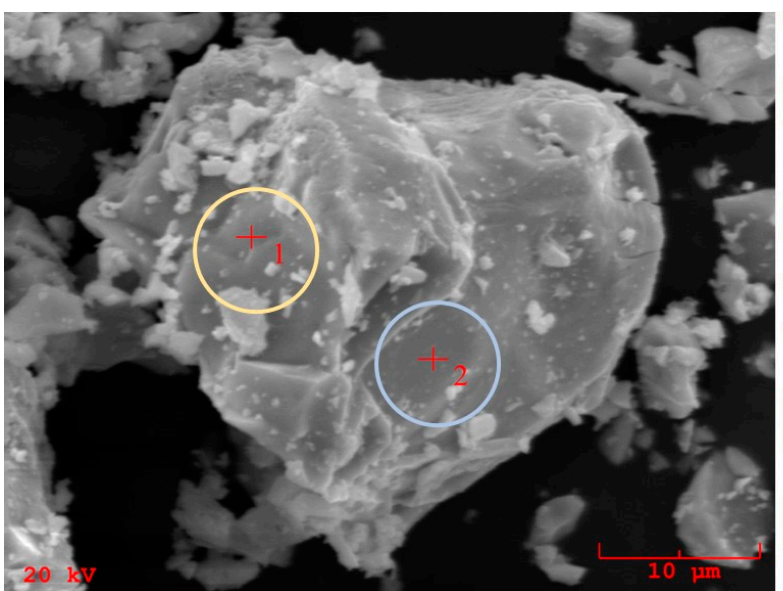

(a)

\begin{tabular}{ccccc}
\hline Element & $\begin{array}{c}\text { Intensity, } \\
(\mathrm{c} / \mathrm{s})\end{array}$ & $\begin{array}{c}\text { Atomic, } \\
\%\end{array}$ & $\begin{array}{c}\text { Concetration, } \\
\text { wt.\% }\end{array}$ & $\begin{array}{c}\text { Error } \\
\text { 2-sig }\end{array}$ \\
\hline $\mathbf{O}$ & 417.00 & 23.796 & 6.135 & 0.053 \\
$\mathrm{Ti}$ & 10403.46 & 51.885 & 40.047 & 0.023 \\
$\mathrm{Ba}$ & 6532.20 & 24.318 & 53.818 & 0.040 \\
\hline Total & - & 100.000 & 100.000 & - \\
\hline & & & & \\
\hline Element & $\begin{array}{c}\text { Intensity, } \\
(\mathbf{c} / \mathbf{s})\end{array}$ & $\begin{array}{c}\text { Atomic, } \\
\%\end{array}$ & $\begin{array}{c}\text { Concetration, } \\
\text { wt.\% }\end{array}$ & $\begin{array}{c}\text { Error } \\
\text { 2-sig }\end{array}$ \\
\hline $\mathbf{O}$ & 2855.90 & 52.193 & 19.482 & 0.026 \\
\hline $\mathrm{Ti}$ & 21742.89 & 34.822 & 38.913 & 0.011 \\
\hline $\mathrm{Ba}$ & 10860.01 & 12.985 & 41.605 & 0.018 \\
\hline Total & - & 100.000 & 100.000 & - \\
\hline & & $(\mathrm{b})$ & & \\
\hline
\end{tabular}

(b)

Figure 6. Cont. 


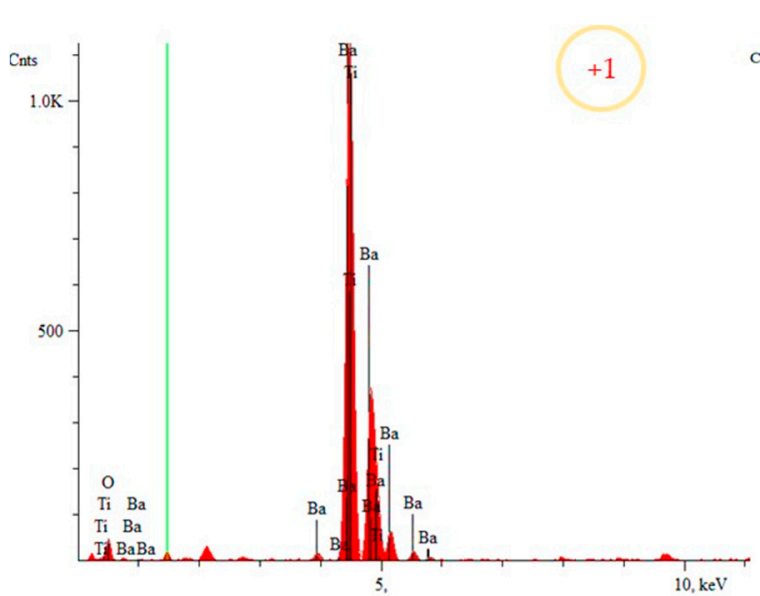

(c)

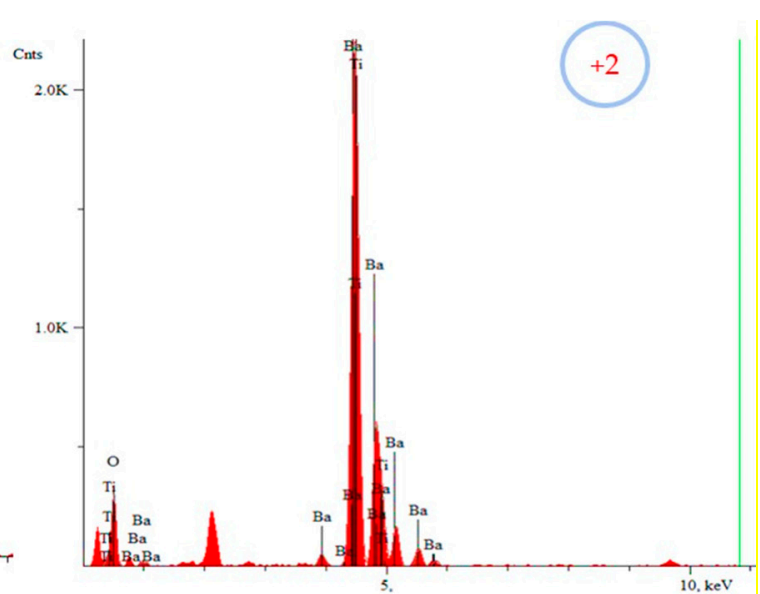

(d)

Figure 6. SEM-EDS points analysis: SEM image of the powder obtained (a), the summary of the content of the specific chemical elements (b) and the EDS spectrum in point 1. (c) and point 2. (d) marked on the SEM image.

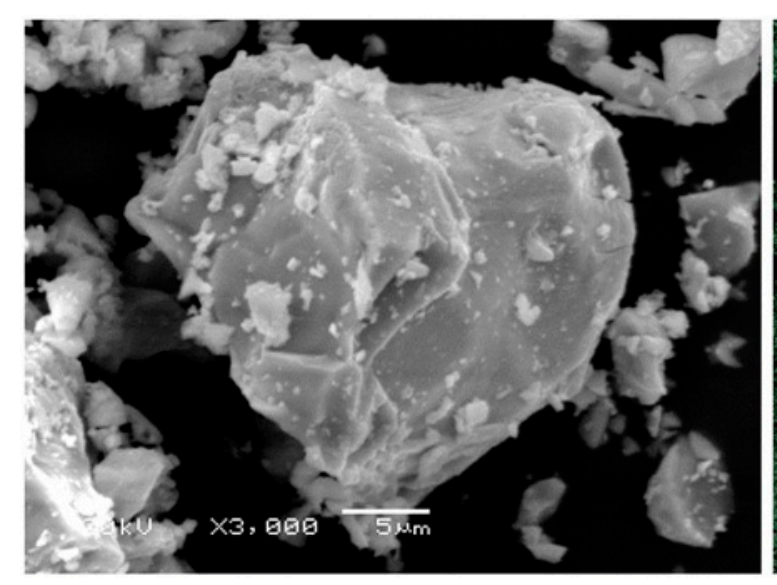

(a)

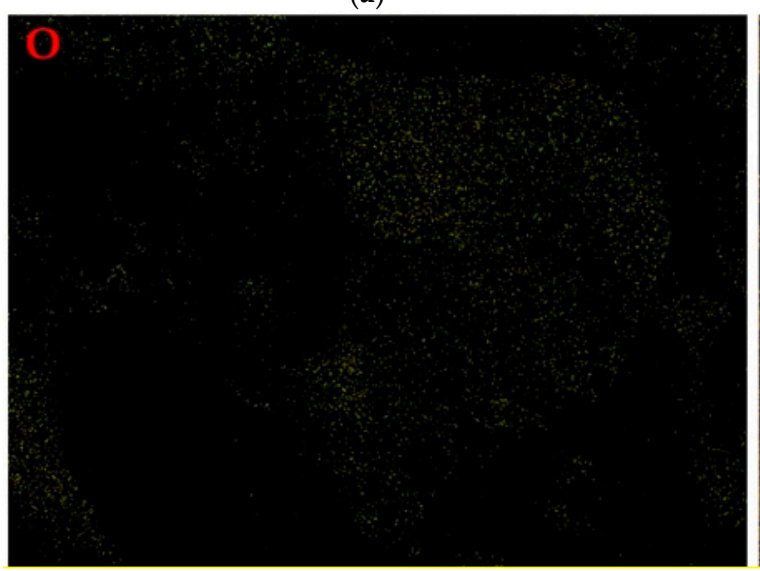

(c)

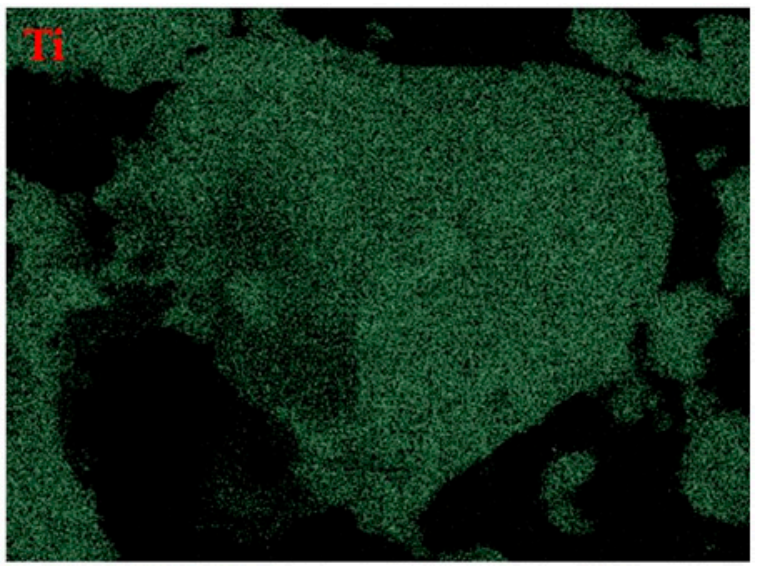

(b)

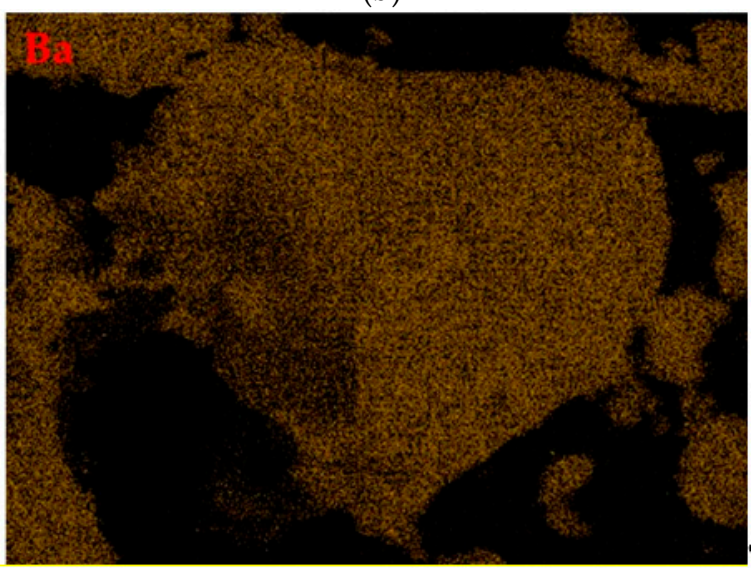

(d)

Figure 7. SEM-EDS elemental mapping for $\mathrm{BaTiO}_{3}$ : SEM image (a) and the corresponding SEM mapping of titanium (b), oxygen (c) and barium (d). 


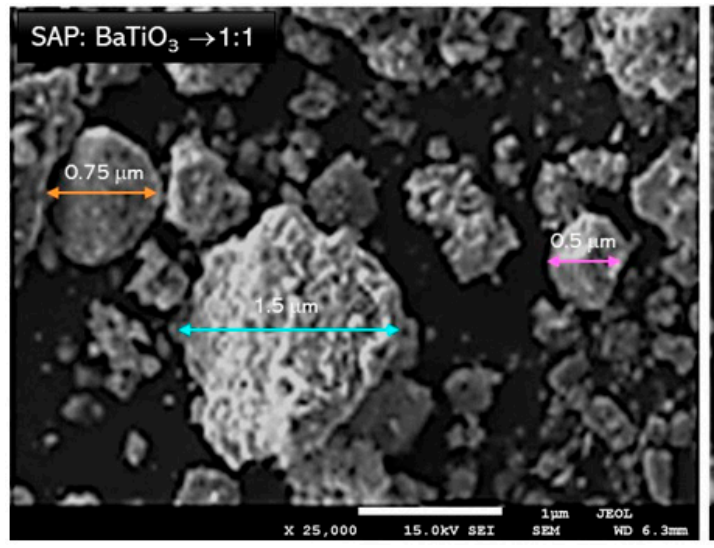

(a)

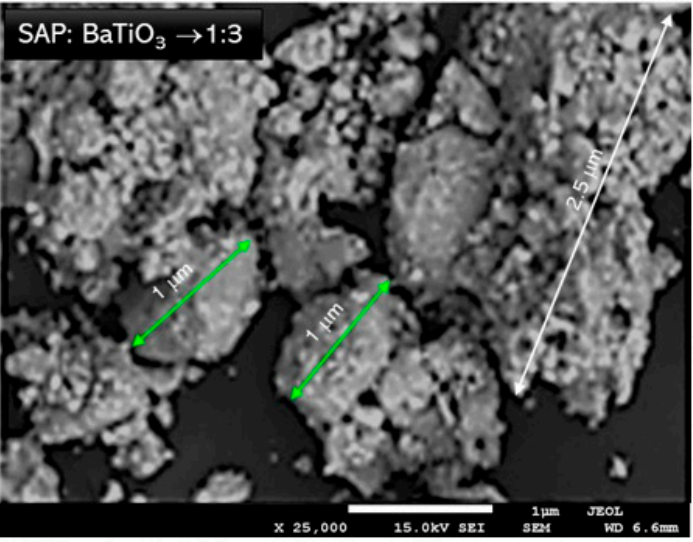

(b)

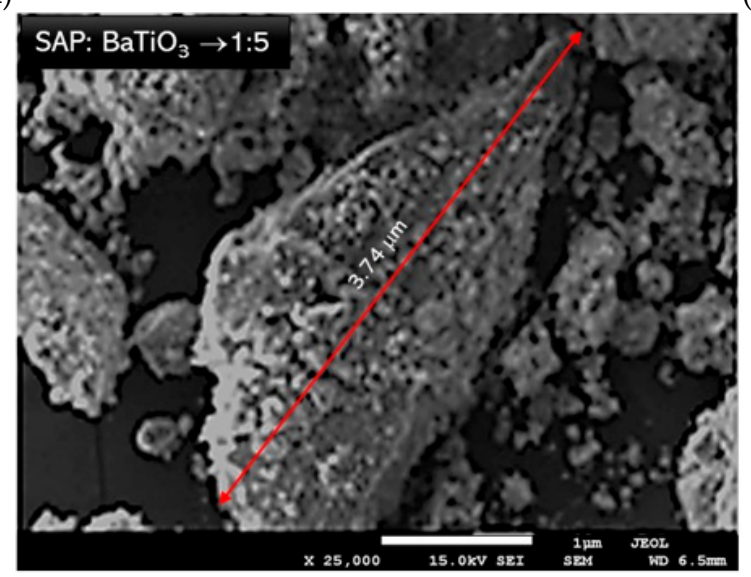

(c)

Figure 8. SEM images of SAP suspensions of barium titanates with different mass ratio of SAP and $\mathrm{BaTiO}_{3}$, i.e., 1:1 (a); 1:3 (b) and 1:5 (c).

Analyzing Figure 5a, it may be observed that the obtained barium titanate powders were characterized by a grainy structure, wherein the grains were micro- and nanometric. The morphology of barium titanates grains after their immersion in water was also determined, which is presented in Figure 5b. Based on the images obtained, it may be concluded that after the immersion in water, the presence of the smallest particles that were visible previously, i.e., in the figure presenting $\mathrm{BaTiO}_{3}$ in a dry state-were not reported. This phenomenon is probably related to the process of aggregation of barium titanate particles in the water environment (this has also been confirmed during the sedimentation investigations presented in further on in this paper). Such an aggregation may affect the sedimentation rate.

Performing EDS analysis allows stating that the elemental composition of the tested barium titanate particles includes elements such as barium, oxygen, and titanium. Any other element has not been observed.

Detailed analysis of the SEM images presented in Figure 8 allowed concluding that SAP suspensions resemble a rather dry form of barium titanate compared with the aqueous suspension. This may be because SAP may act as a stabilizing agent, which prevents the aggregation of barium titanate particles. Furthermore, comparing all the images presented in Figure 8, it may be concluded that any significant impact of the increasing amount of SAP in the dispersion on the structures obtained was not observed. The received structures are comparable. Therefore, it may be stated that the SAP concentration is not a factor determining the size and the shape of the particles obtained. 


\subsection{Investigations on the Sedimentation Process of Barium Titanate Particles in Obtained Suspenions}

Suspensions containing various $\mathrm{SAP} / \mathrm{BaTiO}_{3}$ mass ratios were prepared as described in Section 2.2 of this paper. All the samples were tested to determine the stability of suspensions. For this purpose, the measurements of the sediment heights were conducted after a certain period of time, i.e., after $1 \mathrm{~h}$ and $24 \mathrm{~h}$ after the synthesis, respectively. In Figure 9, the changes in the sediment height as a function of SAP concentration in the tested suspensions are presented as well as the scheme of the sedimentation process being analyzed.

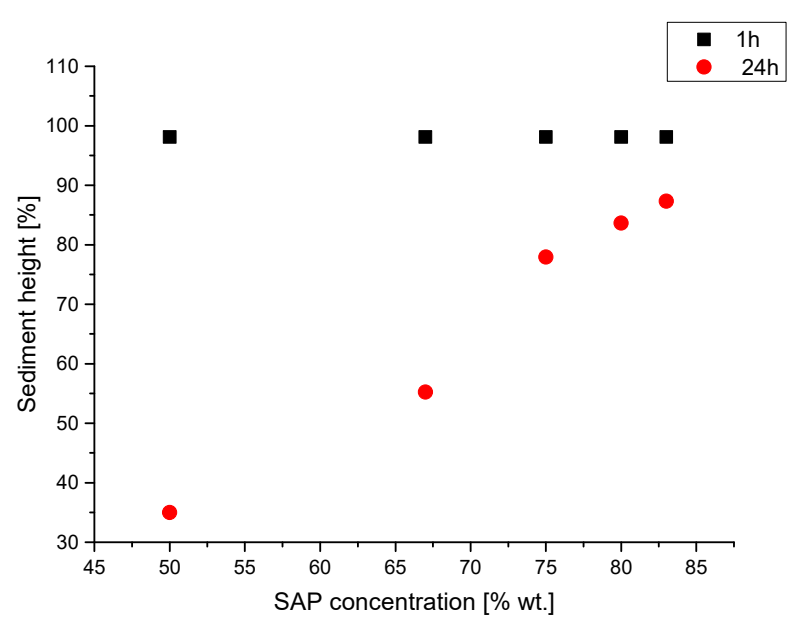

(a)

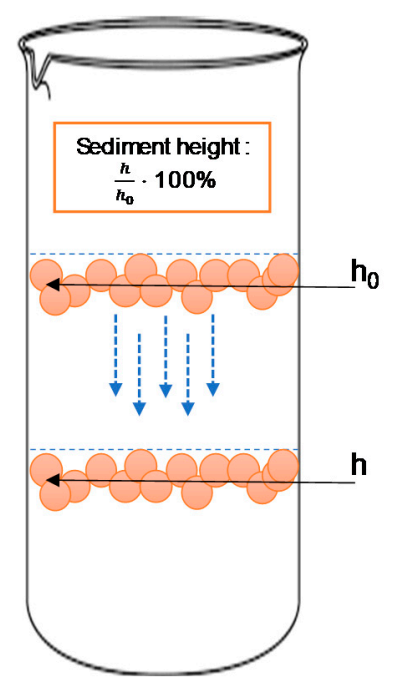

(b)

Figure 9. The sediment heights as a function of the SAP concentration in the tested suspensions (a) and the scheme of the tested sedimentation process $(\mathbf{b})$.

In Figure 9a, the correlation between the SAP concentrations in suspensions with $\mathrm{BaTiO}_{3}$ as a function of sediment height is presented. Measurements after $1 \mathrm{~h}$ of the incubation remained constant. The sedimentation height reached a value equal to $98.1 \%$, independently of the SAP concentration in any particular dispersion. On the other hand, sediment heights determined after $24 \mathrm{~h}$ were significantly influenced by SAP concentrations.

The investigations showed that dispersions with a higher values of SAP mass fraction exhibited lower sedimentation rates. It was noticed that for samples containing 83 wt. $\%$ of SAP $\left(\mathrm{BaTiO}_{3}: \mathrm{SAP}=1: 5\right)$, relatively large sediment heights were observed, reaching values equal to $87.3 \%$. Moreover, concentrations of SAP affected the density of the precipitates; i.e., the higher the SAP concentration, the lower the precipitate density. Particles included in the stable dispersions of $\mathrm{BaTiO}_{3}$ tended to sediment very slowly. According to the Stokes law of sedimentation, bigger particles settle faster than the smaller ones, which float freely in the suspension, leading to the formation of a non-transparent solution above the precipitate.

Furthermore, a higher concentration of polymer solution (SAP) resulted in an enhanced dispersion of barium titanate. Importantly, the presented results of the investigations on SAP dispersions of barium titanate remain in agreement with the results of previously presented analyses of SAP dispersions of calcium titanate [35]. This may lead to a more general conclusion that all perovskite titanates behave in a similar manner when dispersed in SAP.

\section{6. $p H$ Investigations}

In the figures below, results of the $\mathrm{pH}$ measurements are presented. Analyses were conducted from the viewpoint of the changes of SAP concentrations ( $\mathrm{pH}$ was measured 10 days after the synthesis) and the time ( $\mathrm{pH}$ was measured directly after the synthesis). 
The stability and lower sediment density of suspensions with higher SAP concentrations is correlated with $\mathrm{pH}$ values measured. As it may be noticed in Figure 10a, the $\mathrm{pH}$ value depends on the SAP concentration. Strict correlation between $\mathrm{pH}$ and SAP concentration shows that with increasing $\mathrm{SAP}$ concentrations, the $\mathrm{pH}$ value is also slightly increasing. Importantly, higher $\mathrm{pH}$ values favor the formation of porous sediment structures with large spaces among agglomerates. Variable SAP concentrations only slightly affect the $\mathrm{pH}$ values. What is more, the increase in the SAP concentration from $50 \%$ wt. to $83 \%$ wt. does not significantly change the total acidity of the suspension.

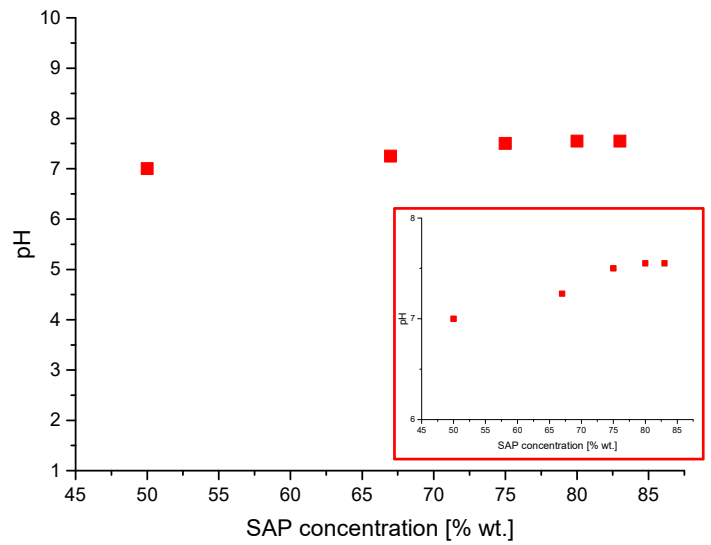

(a)

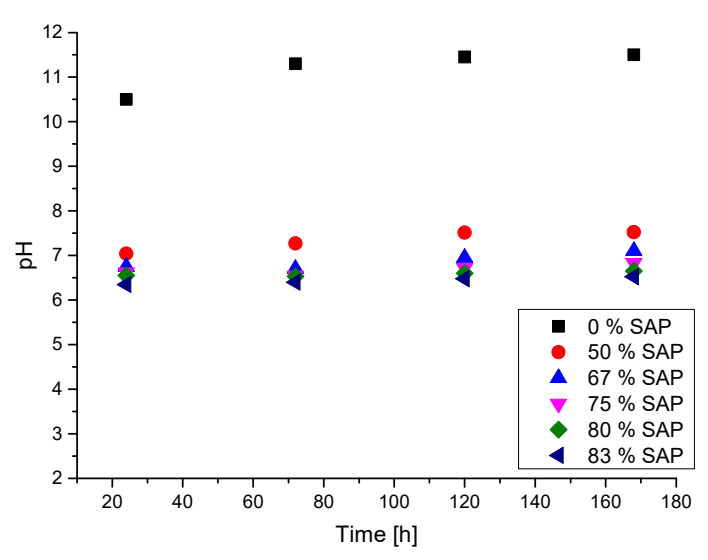

(b)

Figure 10. Changes in the $\mathrm{pH}$ values of $\mathrm{BaTiO}_{3}$ suspensions as a function of SAP concentrations (a) and incubation time (b).

Based on the results presented in Figure 10b, analyses of the $\mathrm{pH}$ changes of the aqueous solution of $\mathrm{BaTiO}_{3}$ without the addition of SAP show that the $\mathrm{pH}$ is changing from 10.5 to 11.5. Comparison of the $\mathrm{pH}$ values of the SAP suspensions of $\mathrm{BaTiO}_{3}$ and the aqueous solution of $\mathrm{BaTiO}_{3}$ indicates the great differences between the $\mathrm{pH}$ values during the whole period of the research. The aqueous solution of barium titanate without the addition of SAP possesses a $\mathrm{pH}$ equal to 10.5, whereas the remaining mixtures upon the addition of SAP reach a $\mathrm{pH}$ value near 6.0-7.0, which indicates the strong influence of the introduced SAP on $\mathrm{pH}$ value. Moreover, the increase in SAP concentration does not significantly change the $\mathrm{pH}$ value of the suspension. Small differences in the $\mathrm{pH}$ values may be noticed among $50 \%$ wt. of SAP and the other concentrations.

Measurement of $\mathrm{pH}$ and Zeta Potential of Aqueous Suspension of Barium Titanate

Figure 11 shows the $\mathrm{pH}$ and zeta potential measurements of $\mathrm{BaTiO}_{3}$ suspension in distilled water.

As can be seen in Figure 11, the $\mathrm{pH}$ of an aqueous suspension of barium titanate is alkaline. This is a result of the hydrolysis of $\mathrm{BaTiO}_{3}$ that proceeds according to the following Equation:

$$
\mathrm{BaTiO}_{3}+\mathrm{H}_{2} \mathrm{O} \leftrightarrow \mathrm{Ba}^{2+}+\mathrm{TiO}_{2}+2 \mathrm{OH}^{-} .
$$

The release of $\mathrm{OH}^{-}$ions results in the increase of the $\mathrm{pH}$ of the suspension and also in the decrease of the zeta potential [38]. For $\mathrm{pH}$ equal to approximately 10.0, the zeta potential decreases, achieving the isoelectric point (IP). Such a big value in which the IP is achieved is caused by the presence of $\mathrm{OH}^{-}$ ions and the simultaneous appearance of barium ions in the suspension. Similar conclusions were drawn by Chiang et al. [39]. 


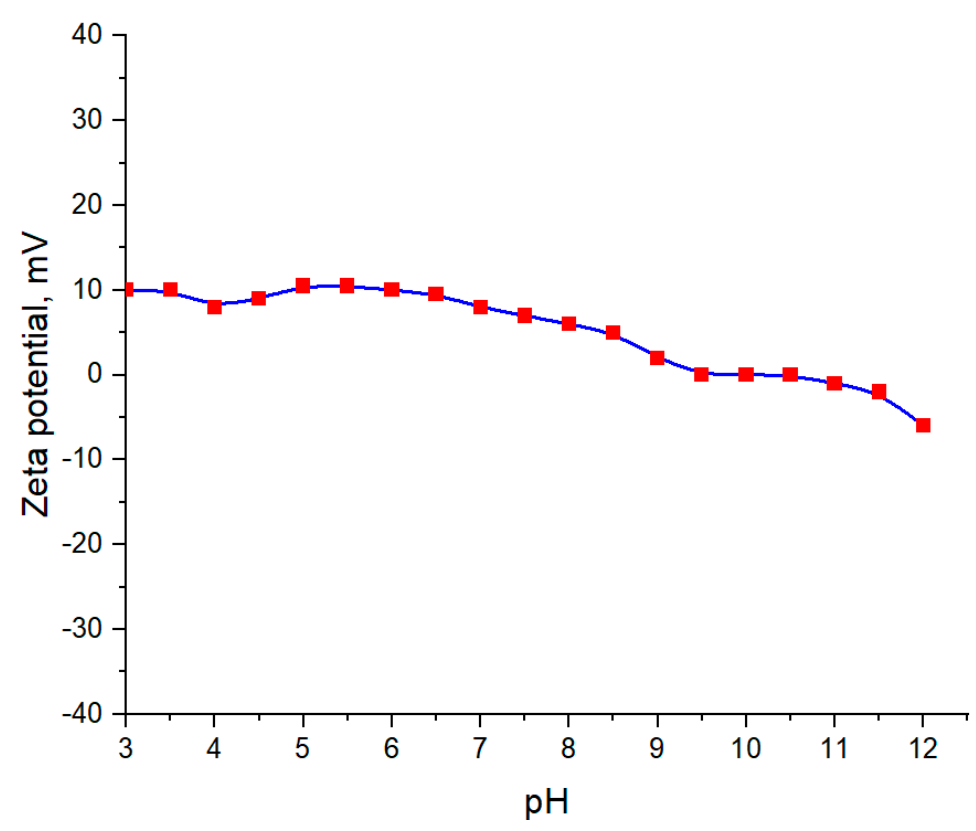

Figure 11. Measurements of $\mathrm{pH}$ and zeta potential of aqueous suspension of $\mathrm{BaTiO}_{3}$ (without $\mathrm{SAP}$ ).

\subsection{Investigations on the Dynamic Viscosity}

In Figure 12, the impact of the SAP introduction into the barium titanate suspension on the viscosity of obtained suspension is presented.

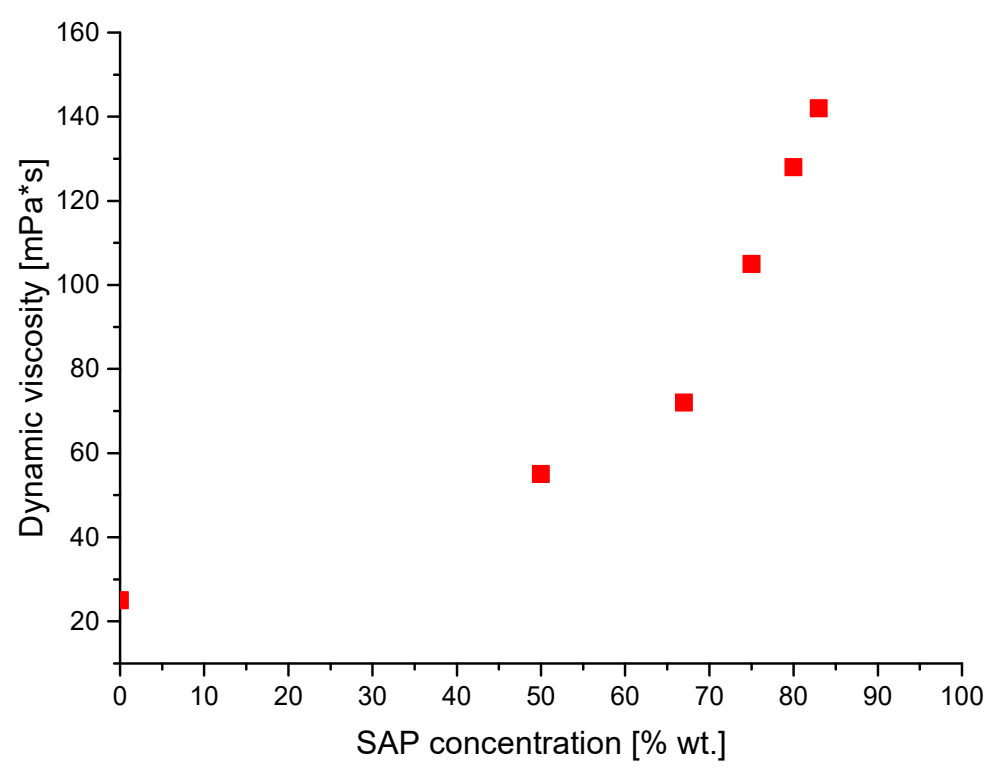

Figure 12. Dynamic viscosity as a function of $\mathrm{SAP}$ concentration in $\mathrm{BaTiO}_{3}$ suspension.

The viscosity value is crucial from the viewpoint of determining the potential applications of the tested suspension. Moreover, suspensions with too low or too high viscosities cause difficulties in handling and during their applications or storage. The change of dynamic viscosity as a function of SAP concentration is shown in Figure 12. The minimum value of viscosity is assigned to the aqueous solution of $\mathrm{BaTiO}_{3}$ without the SAP addition. It may be concluded that the increase in SAP concentration leads to the increase of dynamic viscosity. A low viscosity of the suspension may indicate that the distances between molecules in such a medium are large, and therefore, particles can move freely. On the contrary, an increase of the viscosity results in a reduction of the distances 
between particles, and thus their mobility is diminished and may lead to friction among particles. Molecules of stabilizing agents such as SAP may adsorb to the surface of particles and thus prevent their agglomeration according to the rules of steric and electrostatic effects. As a result, $\mathrm{BaTiO}_{3}$ particles dispersed in SAP are well monodispersed and have sediments with lower speeds, as was observed in sedimentation experiments whose results were presented in Figure 7. This effect can be explained by the Stokes-Einstein law, according to which the higher viscosity of the dispersing phase leads to the lower rates of particles sedimentation. Therefore, variable changes of SAP concentrations, and hence changes of dispersion viscosities, can be used as a regulating agent for particles settling.

\section{Conclusions}

The mechanochemical process proceeding with the use of a ball mill is a suitable technique applied for successful synthesis of perovskites such as barium titanate.

The full conversion of mechanically grinded $\mathrm{BaO}$ and $\mathrm{TiO}_{2}$ powders toward barium titanate occurs after 90 min of milling, which was proven by the crystallographic analysis of the obtained powder. Moreover, the band at $539 \mathrm{~cm}^{-1}$ is characteristic for the stretching vibrations of Ti-O and was observed on an obtained FT-IR spectrum that also confirmed the formation of barium titanate. Furthermore, EDS analysis confirmed that in tested samples there was only barium, oxygen, and titanate.

SAP suspensions of $\mathrm{BaTiO}_{3}$ more closely resemble the dry powder of barium titanate than aqueous suspension.

Analysis of the suspension properties exhibited no significant changes of $\mathrm{pH}$ with the time after the synthesis. On the contrary, the dynamic viscosity of the suspension was increasing with the addition of SAP.

SAP can prevent the aggregation of the particles in colloidal suspensions by electrostatic repulsions between the hydrolyzed acidic groups, or $\mathrm{OH}$ groups form a polymer surfactant conjugated to the surface of particles that also limits the formation of their aggregates. Such a conclusion suggests that SAP in examined suspensions constitutes an excellent stabilizing agent and prevents precipitation or sedimentation of the mineral phase.

These conclusions stay in line with conclusions drawn based on the previous studies of the systems based on calcium titanates [33]. This finding may suggest that groups of perovskite materials such as titanates behave in a similar manner when dispersed in acrylates.

Author Contributions: Conceptualization, P.D., A.S.-K. and B.T.; methodology, P.D. and B.T.; software, S.K.-K., A.D., M.G., R.B. and K.M.; validation, S.K.-K., A.D., M.G. and B.T.; formal analysis S.K.-K., A.D., M.G. and B.T.; investigation, S.K.-K., A.D., M.G., R.B. and K.M.; resources, P.D. and B.T.; data curation, S.K.-K., A.D. and M.G.; writing-original draft preparation, S.K.-K., A.D., M.G. and B.T.; writing-review and editing, S.K.-K., A.D., M.G. and B.T.; visualization, B.T.; supervision, B.T. All authors have read and agreed to the published version of the manuscript.

Funding: This research received no external funding.

Conflicts of Interest: The authors declare no conflict of interest.

\section{References}

1. Buscaglia, V.; Randall, C.A. Size and scaling effects in barium titanate. An overview. J. Eur. Ceram. Soc. 2020, 40, 3744-3758. [CrossRef]

2. Barber, P.; Balasubramanian, S.; Anguchamy, Y.; Gong, S.; Wibowo, A.; Gao, H.; Ploehn, H.J.; Loye, H.C. Polymer Composite and Nanocomposite Dielectric Materials for Pulse Power Energy Storage. Materials 2009, 2, 1697-1733. [CrossRef]

3. Reynolds, G.J.; Kratzer, M.; Dubs, M.; Felzer, H.; Mamazza, R. Electrical Properties of Thin-Film Capacitors Fabricated Using High Temperature Sputtered Modified Barium titanate. Materials 2012, 5, 644-660. [CrossRef]

4. Wodecka-Duś, B.; Adamczyk-Habrajska, M.; Goryczka, T.; Bochenek, D. Chemical and Physical Properties of the BLT4 of Ultra Capacitors-A Suitable Material for Ultracapacitors. Materials 2020, 13, 659. [CrossRef] 
5. Wu, Y.; Isakov, D.; Grant, P.S. Fabrication of Composite Filaments with High Dielectric Permittivity for Fused Deposition 3D Printing. Materials 2017, 10, 1218. [CrossRef]

6. Wei, X.; Liu, Y.; Zhao, D.; Ge, S.S. 3D printing of piezoelectric barium tinatate with high density form milled powders. J. Eur. Ceram. Soc. 2020. [CrossRef]

7. Ziegmann, A.; Schubert, D.W. Influence of the particle size and the filing degree of barium titanate filled silicone elastomers used as potential dielectric elastomers on the mechanical properties and the crosslinking density. Mater. Today Commun. 2018, 14, 90-98. [CrossRef]

8. Uttam, R.; Yadav, N.; Kumar, S.; Dhar, R. Strengthening of columnar hexagonal phase of a room temperature discotic liquid crystalline material by using ferroelectric barium titanate nanoparticles. J. Mol. Liq. 2019, $294,111609$. [CrossRef]

9. Giannakoudakis, D.A.; Barczak, M.; Pearsall, F.; O’Brien, S.; Bandosz, T.J. Composite porous carbon textile with deposited barium titanate nanospheres as wearable protection medium against toxic vapors. Chem. Eng. J. 2020, 384, 123280. [CrossRef]

10. Yang, Y.; Sun, C.; Deng, H.; Fu, Q. Ni(OH) 2 as a novel shell layer material for core-shell dielectric filler based on barium titanate and their dielectric polymer composites in P(VDF-HFP) matrix. Comp. Sci. Tech. 2020, 108274. [CrossRef]

11. Jaglarz, J.; Duraj, R.; Szopa, P.; Cisowski, J.; Czternastek, H. Investigations of white standards by means of bidirectional reflection distribution function and integrating sphere methods. Opt. Appl. 2006, 36, 97-103.

12. Gu, L.; Li, T.; Xu, Y.; Sun, C.; Yang, Z.; Zhu, D.; Chen, D. Effects of the particle size of $\mathrm{BaTiO}_{3}$ fillers on fabrication and dielectric properties of $\mathrm{BaTiO}_{3} /$ Polymer/Al films for capacitor energy-storage application. Materials 2019, 12, 439. [CrossRef] [PubMed]

13. Ishaq, S.; Kanwal, F.; Atiq, S.; Moussa, M.; Azhar, U.; Imran, M.; Losic, D. Advancing dielectric and ferroelectric properties of piezoelectric polymers by combining graphene and ferroelectric ceramic additives for energy storage applications. Materials 2018, 11, 1553. [CrossRef]

14. Kumar, V.; Kumar, A.; Wu, R.-R.; Lee, D.-J. Room-temperature vulcanized silicone rubber/barium titanate-based high-performance nanocomposite for energy harvesting. Mater. Today Chem. 2020, 16, 100232. [CrossRef]

15. Binhayeeniyi, N.; Sukwisute, P.; Nawae, S.; Muensit, N. Energy conversion capacity of barium zirconate titanate. Materials 2020, 13, 315. [CrossRef] [PubMed]

16. Tang, Y.; Wu, C.; Wu, Z.; Hu, L.; Zhang, W.; Zhao, K. Fabrication and in vitro biological properties of piezoelectric bioceramics for bone regeneration. Sci. Rep. 2017, 7, 43360. [CrossRef] [PubMed]

17. Liu, B.; Chen, L.; Shao, C.; Zhang, F.; Zhou, K.; Cao, J.; Zhang, D. Improved osteoblasts growth on osteomimetic hydroxyapatite/ $\mathrm{BaTiO}_{3}$ composites with aligned lamellar porous structure. Mater. Sci. Eng. C Mat. Biol. App. 2016, 1, 8-14. [CrossRef] [PubMed]

18. Baxter, F.R.; Turner, I.G.; Bowen, C.R.; Gittings, J.P.; Chaudhuri, J.B. An in vitro study of electrically active hydroxyapatite-barium titanate ceramics using saos-2 cells. J. Mater. Sci. Mater. Med. 2009, 20, 1697-1708. [CrossRef]

19. Zhang, Y.; Chen, L.; Zhou, K.; Zhang, D. Aligned porous barium titanate/hydroxyapatite composites with high piezoelectric coefficients for bone tissue engineering. Mat. Sci. Eng. C Mater. Biol. Appl. 2014, 1, 143-149. [CrossRef]

20. Koju, N.; Sikder, P.; Galhre, B.; Bhaduri, S.B. Smart Injectable Self-Setting Monetite Based Bioceramics for Orthopedic Applications. Materials 2018, 11, 1258. [CrossRef]

21. Polley, C.; Distler, T.; Detsch, R.; Lund, H.; Springer, A.; Boccaccini, A.R.; Seitz, H. 3D Printing of Piezoelectric Barium Titanate-Hydroxyapatite Scaffolds with Interconnected Porosity for Bone Tissue Engineering. Materials 2020, 13, 1773. [CrossRef] [PubMed]

22. Dubey, A.K.; Basu, B.; Balani, K.; Guo, R.; Bhalla, A.S. Dielectric and pyroelectric properties of $\mathrm{HAp}_{-} \mathrm{BaTiO}_{3}$ composites. Ferroelectrics 2011, 423, 63-76. [CrossRef]

23. Jiao, H.; Zhao, K.; Ma, L.; Tang, Y.; Liu, X.; Bian, T. Preparation and characterization of $\mathrm{BaTiO}_{3} / \mathrm{HA}$ nanocomposite materials by hydrothermal synthesis. J. Alloys Compd. 2017, 693, 221-225. [CrossRef]

24. Jelinek, M.; Vanek, P.; Tolde, Z.; Buixaderas, E.; Kocourek, T.; Studnicka, V.; Drahokoupil, J.; Petzelt, J.; Remsa, J.; Tyunina, M. PLD preparet bioactive $\mathrm{BaTiO}_{3}$ films on TiNb implants. Mater. Sci. Eng. C 2017, 70, 334-339. [CrossRef]

25. Stojanovic, B.D.; Simoes, A.Z.; Paiva-Santos, C.O.; Jovalekic, C.; Mitic, V.V.; Varela, J.A. Mechanochemical synthesis of barium titanate. J. Eur. Ceram. Soc. 2005, 25, 1985-1989. [CrossRef] 
26. Lazarevic, Z.; Romcevic, N.; Vijatovic, M.; Paunovic, N.; Romcevic, M.; Stojanovic, B.; Dohcevic-Mitrovic, Z. Characterization of barium titanate ceramic powders by raman spectroscopy. Acta Phys. Pol. A 2009, 115, 808-810. [CrossRef]

27. Sydorchuk, V.; Khalameida, S.; Zazhigalov, V. Mechanochemical synthesis of barium titanate and its photocatalytic properties. Ann. Univ. Mariae Curie-Skłodowska 2009, 64, 159-168. [CrossRef]

28. Ohara, S.; Kondo, A.; Shimoda, H.; Sato, K.; Abe, H.; Naito, M. Rapid mechanochemical synthesis of fine barium titanate nanoparticles. Mater. Lett. 2008, 62, 2957-2959. [CrossRef]

29. Tripathy, S.S.; Raichur, A. Dispersibility of barium tsitanate suspension in the presence of polyelectrolytes: A review. J. Dispers. Sci. Technol. 2008, 29, 230-239. [CrossRef]

30. Liu, G.; Zhang, D.; Button, T.W. Preparation of concentrated barium titanate suspensions incorporating nano-sized powders. J. Eur. Ceram. Soc. 2010, 30, 171-176. [CrossRef]

31. Blanco Lopez, M.C.; Rand, B.; Riley, F.L. Polymeric Stabilization of Aqueous Suspensions of Barium Titanate. Part II: Effect of Polyelectrolyte Concentration. J. Eur. Ceram. Soc. 2000, 20, 1587-1594.

32. Blanco Lopez, M.C.; Rand, B.; Riley, F.L. Polymeric Stabilization of Aqueous Suspensions of Barium Titanate. Part I: Effect of pH. J. Eur. Ceram. Soc. 2000, 20, 1579-1586. [CrossRef]

33. Dulian, P.; Bakk, W.; Wieczorek-Ciurowa, K.; Kajtoch, C. Dielectric properties of vanadium doped barium titanate synthesized via high-energy ball milling. Mater. Sci. Pol. 2014, 32, 257-263. [CrossRef]

34. Tyliszczak, B.; Piątkowski, M.; Dulian, P.; Bialik-Wąs, K.; Bogdał, D.; Wieczorek-Ciurowa, K.; Wzorek, Z.; Sobczak-Kupiec, A. A novel class of dispersants for colloidal processing of hydroxyapatite. Czas. Tech. Chem. 2011, 108, 225-228.

35. Tyliszczak, B.; Gaca, K.Z.; Sobczak-Kupiec, A.; Dulian, P. Mechanochemical synthesis and investigations of calcium titanate powders and their acrylic dispersions. J. Eur. Ceram. Soc. 2014, 34, 2259-2264. [CrossRef]

36. Sun, D.; Jin, X.; Liu, H.; Zhu, J.; Zhu, Y.; Zhu, Y. Investigation on FTIR spectrum of barium titanate ceramics doped with alkali ions. Ferroelectrics 2007, 355, 145-148. [CrossRef]

37. Ashiri, R. Detailed FT-IR spectroscopy characterization and thermal analysis of synthesis of barium titanate nanoscale particles through a newly developed process. Vib. Spectrosc. 2013, 66, 24-29. [CrossRef]

38. Beaudrouet, E.; Vivet, A.; Lejeune, M.; Santerne, C.; Rossignol, F.; Dossou-Yovo, C.; Mougenot, M.; Noguera, R. Stability of aqueous barium titanate suspensions for MLCC inkjet printing. J. Am. Ceram. Soc. 2014, 97, 1248-1255. [CrossRef]

39. Chiang, C.W.; Jean, J.H. Effects of barium dissolution of dispersing aqueous barium titanate suspensions. Mater. Chem. Phys. 2003, 80, 647-655. [CrossRef] 